\title{
An outbreak of COVID-19 associated with a fitness centre in Saskatchewan: Lessons for prevention
}

\author{
Maureen Anderson $1,2 \star$, Ashok Chhetri ${ }^{1,2}$, Edith Halyk ${ }^{3}$, Amanda Lang ${ }^{4}$, Ryan McDonald ${ }^{4}$, \\ Julie Kryzanowski ${ }^{1,5}$, Jessica Minion ${ }^{4}$, Molly Trecker ${ }^{2}$
}

\section{Abstract}

Background: An outbreak of the coronavirus disease 2019 (COVID-19) occurred in Saskatchewan from September 12 to October 20, 2020. The index event, attendance at a local gym, seeded six additional clusters/outbreaks in multiple settings. These included a high school, a hospital, three workplaces (A, B and C) and several households. The overall cluster comprised 63 cases, 27 gym members and an additional 36 second, third and fourth generation cases.

Methods: All outbreak-related, laboratory-confirmed cases of COVID-19 were included in the analysis. Local public health authorities interviewed all cases and contacts and conducted environmental investigations of the fitness facility. We used descriptive epidemiological methods to understand transmission dynamics of the gym-associated cluster using case investigation, contact investigation and laboratory data, including whole genome sequencing.

Results: Sequencing data confirmed the unique lineage of cluster-related cases ( $n=32$ sequenced; severe acute respiratory syndrome coronavirus 2 [SARS-CoV-2] lineage B.1.1.72). In addition to gym attendance, infectious cases attended high school and were involved in other activities. Despite ongoing transmission in the fitness facility, no secondary cases were identified in the high school where four student belonging to the cluster attended class during their infectious period.

Conclusion: We describe an outbreak of COVID-19 where the index case(s) attended a fitness facility, and further spread occurred for 38 days despite active-case finding and isolation of positive cases over this period. Due to gym attendance over time, short-term closing and cleaning may not interrupt chains of transmission. Targeted, preventive public health action in fitness facilities may be warranted. Control measures worked to limit in-school acquisition.
This work is licensed under a Creative Commons Attribution 4.0 International License.

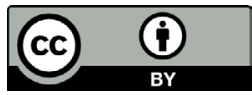

Affiliations

${ }^{1}$ Department of Community Health and Epidemiology, University of Saskatchewan, Saskatoon, SK

2 Saskatchewan Health Authority, Population Health, Saskatoon, SK

${ }^{3}$ Saskatchewan Health Authority, Public Health Services, Yorkton, SK

${ }^{4}$ Roy Romanow Provincial Laboratory, Regina, SK

${ }^{5}$ Population Health Branch, Saskatchewan Ministry of Health, Regina, SK

\section{*Correspondence:} maureen.anderson@usask.ca

Suggested citation: Anderson M, Chhetri A, Halyk E, Lang A, Kryzanowski J, Minion J, Trecker M. An outbreak of COVID-19 associated with a fitness centre in Saskatchewan: Lessons for prevention. Can Commun Dis Rep 2021;47(11):485-90. https://doi.org/10.14745/ccdr.v47i11a08

Keywords: COVID-19, SARS-CoV-2, gym, ventilation, physical distancing, cluster investigation, whole genome sequencing, active case finding, public health

\section{Background}

In September 2020, public health officials in Saskatchewan observed an increase in the number of laboratory-confirmed cases of the coronavirus disease 2019 (COVID-19) in city X. Five cases reported over a two-day period had a common link to a local gym. The date of onset of the index case was September 12, and an outbreak was declared on September 27. A total of 63 outbreak-related cases were identified with dates of onset from September 12 to October 20, 2020. Cases were confirmed to be related through whole genome sequencing. The majority $(79.4 \%)$ of cluster-related cases were 18 to 64 years old, and $54.0 \%$ identified as male; all cases recovered. Secondary cases $(n=23)$ were largely household contacts of gym goers.

Outbreaks of COVID-19 in fitness centres/gyms have occurred in many jurisdictions throughout the pandemic. Gyms are high-risk settings that facilitate the severe acute respiratory 
syndrome coronavirus 2 (SARS-CoV-2) transmission. Researchers hypothesize that several risk factors contribute to viral transmission in fitness facilities:

- The length of time individuals typically spend in a gym (about 50 minutes)

- Increased respiration during physical activity

- Viral load of infectious person

- Facility size and ventilation

- Increased risk associated with group exercise classes, particularly where participants/instructors are in close proximity and/or speak loudly over music (1-6)

Of note, analytic studies examining the risk of communityacquired SARS-CoV-2 infection and gym attendance have not consistently pointed to an increase in disease acquisition among gym goers. For example, a study conducted in Oslo, Norway, randomly allocated individuals to either access to a fitness facility or no access to a fitness facility. Test positivity rates between the two groups after a 14-day period did not differ substantially (zero cases in the no access; one case not acquired in the fitness facility within the group with access) (7). Another recent case-control study found that, even after adjusting for potential confounding factors, attendance at a gym in the 14-day period prior to illness onset did not statistically significantly differ between symptomatic individuals who tested positive for SARS-CoV-2 infection and individuals who tested negative (8).

Public health conducts detailed work when investigating clusters of illness in order to mitigate the spread of disease and prevent future outbreaks. Particularly when the investigation involves a novel pathogen associated with a worldwide pandemic, thorough cluster investigations can serve to provide important data for understanding the spread and risk of acquisition. The objectives of our outbreak investigation were to identify and isolate all SARS-CoV-2 infectious cases to prevent further transmission and to understand the underlying conditions that may have contributed to viral transmission at the fitness facility, providing data for preventive action.

\section{Methods}

The Roy Romanow Provincial Laboratory (RRPL) uses reverse transcription polymerase chain reaction (RT-PCR) tests to identify the presence of SARS-CoV-2 in all submitted nasopharyngeal specimens. Under the provincial Public Health Act, 1994, all laboratory-confirmed cases of SARS-CoV-2 infection must be reported to local public health authorities. Through individual case interviews, using a standardized data collection worksheet, local authorities collect information on case demographics, date of symptom onset and all activities undertaken by the case during the infectious period.

In this investigation, trained public health nurses undertook contact-tracing interviews for all close contacts named by cases. Cases were required to self-isolate for 14-days from date of last contact with a confirmed case in order to break subsequent chains of transmission. In addition, all close contacts were offered testing. A case was defined as a lab-confirmed case of COVID-19 with symptom onset of September 12, 2020, or later, epidemiologically linked to the fitness centre. Epi-linked cases either attended the gym in person or identified as part of a transmission chain linked to a gym attendee.

We extracted laboratory data from the provincial laboratory information system, a repository of all laboratory results. Canada's National Microbiology Laboratory supplied whole genome sequencing data for all outbreak-related specimens.

We used descriptive epidemiology (counts, rates, proportions, epidemic curve) to understand the burden and timing of disease in the index and associated clusters and to characterize the cases and their outcomes. We used both detailed case and cluster investigation data to create a visual of the index cluster and transmission to other clusters (Figure 1). Whole genome sequencing data served to verify whether the cluster-associated cases were related. Additional qualitative contextual information provided by public health investigators, including public health nurses and public health inspectors, were included in the descriptive analysis.

\section{Figure 1: Visualization of the index cluster and the spread to other clusters}

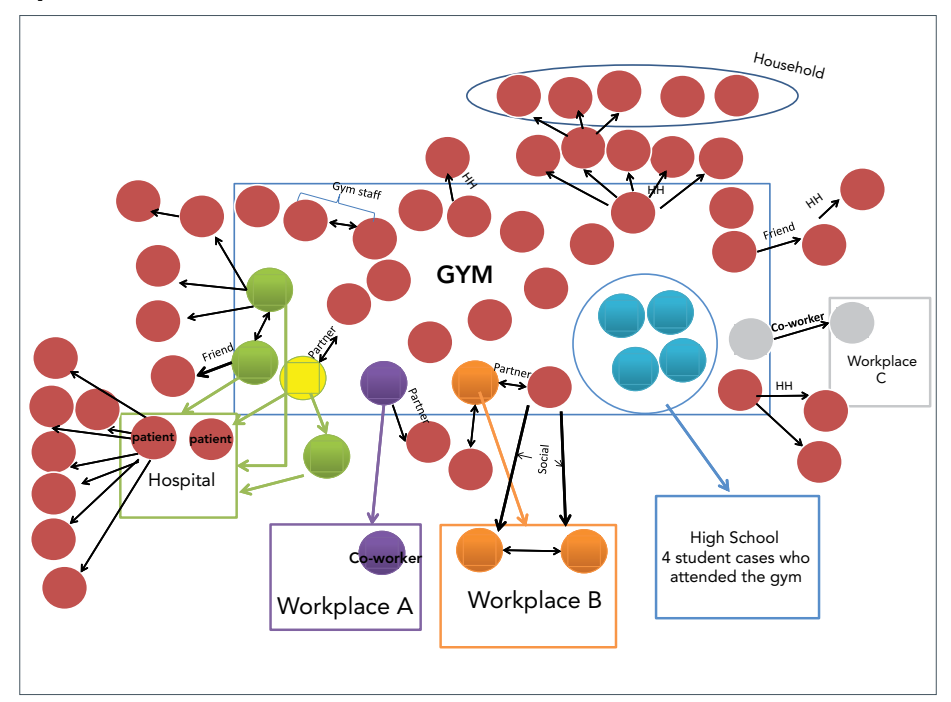

Abbreviation: $\mathrm{HH}$, household

\section{Results}

The majority (79.4\%) of the 63 cluster-related cases were 18 to 64 years old, and $54.0 \%$ were male. Just over half (57.1\%) were not fitness centre members. Secondary cases were largely household contacts. No cases were hospitalized or died (see Table 1 for a description of outbreak-associated cases; see Figure 2 for an epidemic curve showing case data by date of symptom onset). 
Table 1: Descriptive epidemiology of COVID-19 cases arising from attendance at a gym as the index exposure, City X, Saskatchewan, September 12 to October 20, $2020(n=63)$

\begin{tabular}{|c|c|c|c|}
\hline Variable & Category & $\mathbf{n}$ & $\%$ \\
\hline \multirow{3}{*}{ Age } & Children ( $<18$ years) & 8 & 12.6 \\
\hline & Adults (18-64 years) & 50 & 79.4 \\
\hline & Seniors (65+ years) & 5 & 7.9 \\
\hline \multirow{2}{*}{ Sex } & Male & 34 & 54.0 \\
\hline & Female & 29 & 46.0 \\
\hline \multirow{2}{*}{$\begin{array}{l}\text { Gym } \\
\text { member }\end{array}$} & Yes & 27 & 42.9 \\
\hline & No & 36 & 57.1 \\
\hline \multirow{5}{*}{$\begin{array}{l}\text { Associated } \\
\text { cluster } \\
\text { settings }\end{array}$} & High school & 4 & 6.3 \\
\hline & Hospital & 13 & 20.6 \\
\hline & Workplace A & 2 & 3.2 \\
\hline & Workplace B & 3 & 4.8 \\
\hline & Workplace C & 2 & 3.2 \\
\hline \multirow{3}{*}{ Case type } & Secondary & 23 & 36.5 \\
\hline & Tertiary & 11 & 17.5 \\
\hline & Quaternary & 2 & 3.2 \\
\hline \multirow{3}{*}{ Outcome } & Hospitalized & 0 & 0 \\
\hline & Not hospitalized, recovered & 57 & 100.0 \\
\hline & Died & 0 & 0 \\
\hline $\begin{array}{l}\text { Gym attack } \\
\text { rate }\end{array}$ & $\begin{array}{l}\text { Cases/all gym-members who } \\
\text { attended the gym in the first few } \\
\text { weeks of investigation (September } \\
20-27 \text { and October } 1-3 \text { ) }\end{array}$ & $27 / 251$ & 10.8 \\
\hline
\end{tabular}

Figure 2: Epidemic curve of COVID-19 outbreak associated with gym attendance, September 12 to October 20, 2020, by date of symptom onset or collection date (where asymptomatic) and cluster affiliation, city $X$, Saskatchewan $(n=63)$

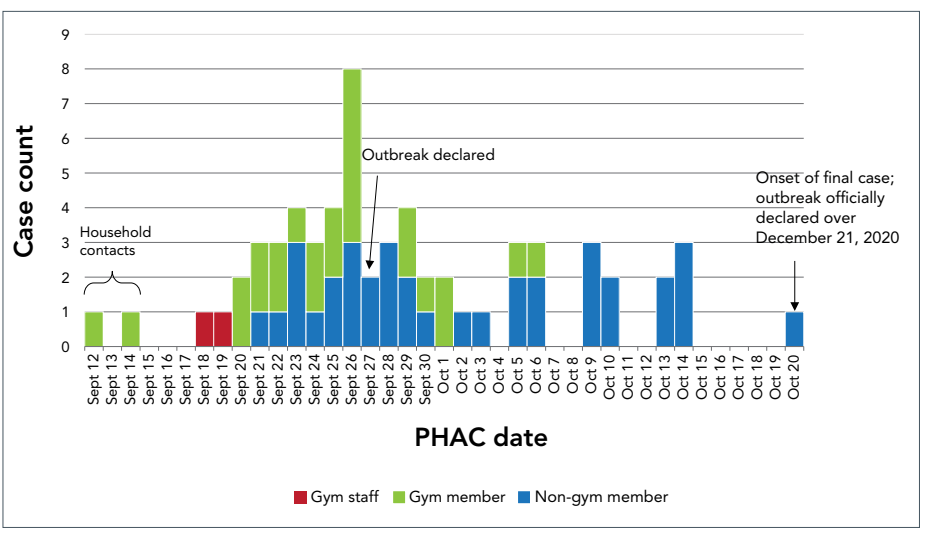

Abbreviation: PHAC, Public Health Agency of Canada

The index case date of symptom onset was September 12. Two days later, a gym attendee and household contact of the index case became ill. Four days after that another gym attendee became ill; transmission within the facility continued for several more weeks.

The index case reported engaging in individual physical activity (not group exercise) while at the gym and reported adherence to the recommended public health interventions. Mask wearing in fitness facilities was not mandated through a provincial health order until November 6, 2020.

Following declaration of the outbreak on September 27, information was gathered from the gym on attendance over the week prior and following the outbreak declaration (September 20 to October 3). The gym reported that 251 people attended over this time period for an overall attack rate of approximately $11 \%$ among gym goers $(27 / 251 ; 10.8 \%)$.

Cases directly linked to the gym continued to occur until October 20 (total $n=27$ individuals). Two staff members were infected over the time period and reported mainly individual workouts (bodybuilding and cardio).

Four cases who attended the gym multiple times between September 16 and 24 also attended a large regional high school $(n=590)$ while infectious. In spite of active-case finding, including testing of approximately 100 students at the high school, there was no evidence of secondary transmission in the school. These cases also took part in other high-risk activities while infectious at the school, including participating in football and hockey and attending at least four different class cohorts. Despite this, there was no evidence of additional cases at the school.

Public health measures to reduce SARS-CoV-2 transmission at the school were numerous. They included the following: mandatory masking in the classroom for Grades 4 and higher, including in the gymnasium; a "five block" schedule where students were placed in small learning groups; in-class lunch eating only; and staggered breaks throughout the day. After the four infectious cases were discovered, the school moved to online learning for approximately two weeks.

\section{Laboratory investigations}

Whole genome sequencing data for 32 of the cluster-related cases is shown in Figure 3. Sequence data analysis assigned all 32 specimens to pangolin lineage using Pangolin v2.1.7 and PangoLEARN data release January 16, 2021 (Centre for Genomic Pathogen Surveillance, United Kingdom), with nine unique single nucleotide variant profiles. SARS-CoV-2 in lineage B.1.1 has been identified worldwide and has been frequently found in sequences elsewhere in Saskatchewan. To date, the provincial laboratory has not identified SARS-CoV-2 lineage B.1.1 with the same unique nucleotide variant profile elsewhere in Saskatchewan, but this does not preclude its presence $(9,10)$. 
Figure 3: Whole genome sequencing data

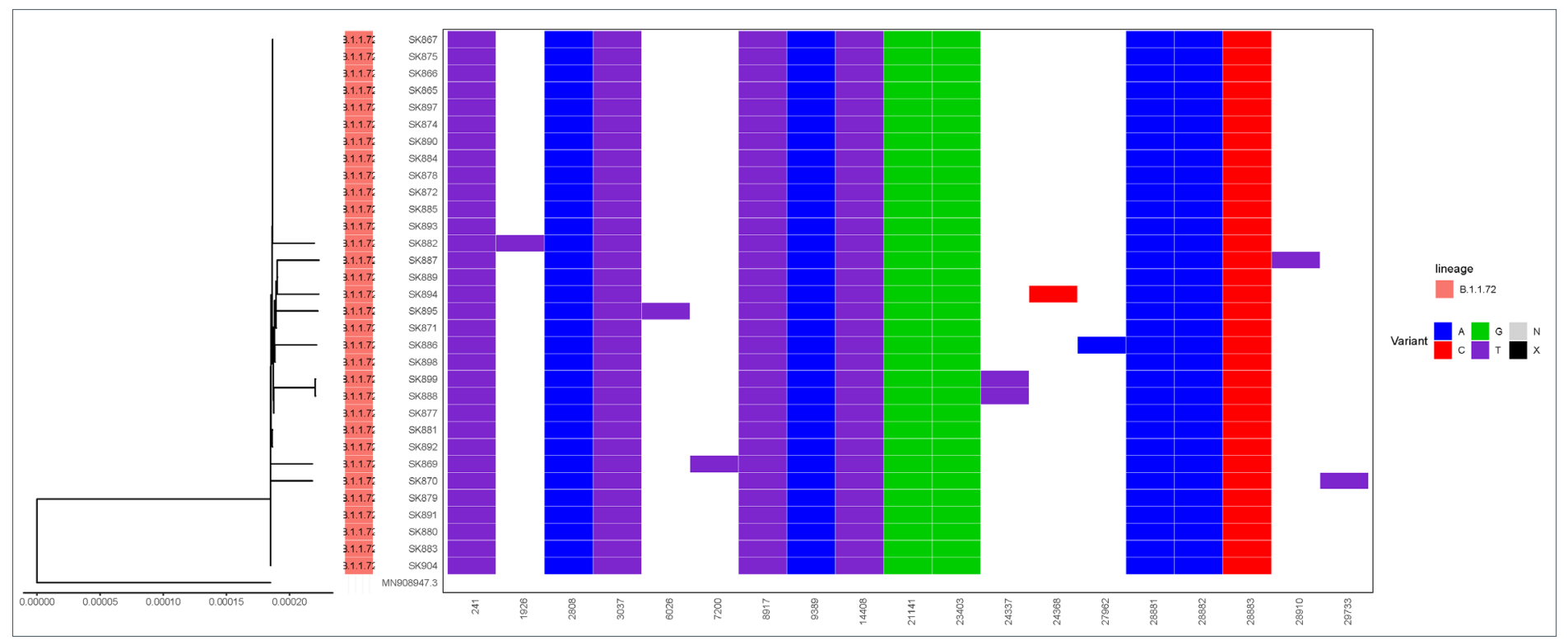

\section{Environmental investigation}

With the collaboration of the gym owner, public health inspectors worked to investigate, respond and mitigate viral spread at the gym. Public health closed the gym on September 26 at 22:00 hours and permitted it to reopen on September 30 at 23:59 hours. Public health inspectors provided recommendations to the owner (physical distancing of patrons/equipment, cleaning product ingredient recommendations, frequency of cleaning) and, in accordance with government guidelines (11), permitted the gym to reopen following a deep clean of the facility.

The owner, in discussions with the local public health inspector, reported that gym members had adhered to physical distancing recommendations, but may not have adhered to the masking guidelines (provincial mask mandates were not in effect at the time). The inspector noted that not all gym equipment was spaced two metres apart; some cardio equipment was moved in order to comply with distancing regulations. Disinfection of the gym by electrostatic sprayer reportedly occurred; however, it was not clear how systematically or how frequently this took place.

Inspection of the air ventilation system found two main parts: the system in the main gym area was installed in 2013, while the system in the second, smaller area was installed in 2019. The inspection noted the air handling system was adequate for proper ventilation; however, actual airflow and air-exchange measurements were not measured. The gym owner reported changing the air filters every two weeks. Of note, the public health inspector indicated that the ventilation in the gym may have played a role in the outbreak: this particular gym is located in a low-ceiling basement setting.

\section{Discussion}

An outbreak of COVID-19 was associated with attendance at a gym in a Canadian city. A total of 63 outbreak-related cases, confirmed through whole genome sequencing, were identified with onset dates from September 12 to October 20, 2020; all cases recovered. Although outbreak-related cases attended school while infectious and in spite of active-case finding, including testing of approximately 100 students at the high school, there was no evidence of secondary transmission within the school. In this outbreak, gym attendance did not result in a one-time superspreading event. As a common cohort attends gyms over time, we hypothesize that short-term closing and cleaning may not be sufficient to interrupt chains of transmission in fitness facilities.

Public health investigations, including thorough case investigation and active-case finding by trained public health nurses, contact tracing, isolation of exposed individuals, inspection, education, surveillance and testing, all combined to control the spread of COVID-19. Despite that cases from the gym also attended high school classes and took part in sports activities while infectious, no viral transmission occurred within the school.

At the time the infectious cases attended school, the school had implemented numerous public health measures intended to reduce viral transmission. It is hypothesized that these measures reduced in-school spread; combined with growing evidence of children being less efficient viral transmitters when infected with wild type virus $(12,13)$, though this rationale may be less applicable to older teenagers. 
In this propagated outbreak investigation, we found gym attendance did not result in a one-time superspreading event. Dates of symptom onset for gym attendees were spread out over time (Figure 2), indicative of a cohort of gym goers intermingling at different times. Due to the nature of ongoing gym attendance over time, short-term closing and cleaning, as recommended in government guidelines for gym and fitness centres (11), will not necessarily interrupt chains of transmission.

Gyms/fitness facilities have been identified as high-risk settings for SARS-CoV-2 transmission in previous outbreak reports $(1,3,4)$. Outside of outbreak reports, however, studies attempting to quantify the community-associated risk of infection in gyms have not uniformly demonstrated an increased risk. In the absence of an infectious case linked to a facility, as was the case in the Helsingen et al. study (7), it is not surprising test positivity rates among the gym goers and the non-gym goers remained low. A case-control study conducted by the Centers for Disease Control and Prevention (CDC) included only symptomatic individuals, that is, those who tested negative were controls and those who tested positive were cases (8). Given that study authors recruited only symptomatic positive individuals at the time of testing, it is possible a systematic selection bias occurred. Asymptomatic, infectious individuals (not sampled in the study) may have been more likely to visit a fitness facility prior to testing than symptomatic individuals (population under study) at the time of testing who may have been less likely to visit a fitness centre prior to testing if they were feeling unwell. This bias may have artificially decreased the risk associated with this setting type among study participants.

Cluster investigations are important for understanding the transmission dynamics of pathogens. Public health investigations have repeatedly demonstrated that there is a risk for infection with SARS-CoV-2 in fitness facilities. In the cluster described in this article, we hypothesize that the following factors likely contributed to viral transmission in the facility: non-adherence to some recommended public health measures; outbreak occurring prior to provincial mask mandate in fitness facilities; and low ceilings/basement setting with potentially inadequate ventilation.

Our study has limitations. We were not able to test all close contacts (investigators estimate we tested approximately $70 \%)$. A complete list of gym members was not available, and not all named contacts accepted a test or were receptive to public health follow-up. In addition, a fitness-facility-specific questionnaire was not administered to all cluster-involved cases because of public health workload. This limits our ability to quantify the impact of other variables that may be of importance, such as the amount of time spent at the gym and the number of visits to the facility during the period of interest.

It is likely that the increased risk of SARS-CoV-2 infection associated with fitness facility attendance is multifactorial. Gym attendance, by its very nature, occurs not just at one point in time and space (generating superspreading events); rather, risk of infection is associated with ongoing exposure among gym members. In this instance, public health measures of closing and cleaning fitness facilities may not have been sufficient. Targeting fitness facilities could be useful in reducing transmission, for example, proactive inspection of ventilation systems; client manifests (list of all gym attendees) required to be reported to public health; use of technology, such as QR codes, to track clients; restricted activities in gyms known to be higher risk (spin class, group fitness); and implementing active-case finding/rapid point-of-care testing, particularly among staff and instructors have a demonstrated higher risk of transmission than attendees (3).

\section{Conclusion}

Indoor fitness facilities are high-risk settings for SARS-CoV-2 viral transmission. Active-case finding using rapid point-of-care test kits at fitness facilities or routine testing of all gym members when community transmission rates are high may be effective strategies to consider in high-risk settings. As immunization against SARS-CoV-2 infection becomes routinely available at the population level, immunization status may be a useful piece of information to collect in such high-risk settings. It is likely immunized individuals will shed less virus; however, adherence to public health measures (such as deep cleaning, disinfection of equipment, physical distancing, reduction in group fitness activities and capacity limits) and mask use where ventilation is poor will continue to be important. This recommendation may extend to other settings such as places of worship and other congregate settings.

\section{Authors' statement}

$\mathrm{EH}, \mathrm{AL}, \mathrm{RM}$ and $\mathrm{MT}$ - Conducted data collection

MT, AC, JM, RM and MA - Prepared the materials and performed the analysis

MA - Wrote the manuscript

All authors contributed to the study conception and design, the interpretation, commented on drafts and contributed wording, read and approved the final manuscript.

The content and view expressed in this article are those of the authors and do not necessarily reflect those of the Government of Canada.

\section{Competing interests}

The authors declare that they have no conflict of interest.

\section{Funding}

The authors gratefully acknowledge the Saskatchewan Health Authority, Population Health and the Roy Romanow Provincial Laboratory for in-kind support. 


\section{References}

1. Bae S, Kim H, Jung TY, Lim JA, Jo DH, Kang GS, Jeong SH, Choi DK, Kim HJ, Cheon YH, Chun MK, Kim M, Choi S, Chun C, Shin SH, Kim HK, Park YJ, Park O, Kwon HJ. Epidemiological characteristics of COVID-19 outbreak at fitness centers in Cheonan, Korea. J Korean Med Sci 2020;35(31):e288. DOI PubMed

2. Pung R, Chiew CJ, Young BE, Chin S, Chen MI, Clapham HE, Cook AR, Maurer-Stroh S, Toh MP, Poh C, Low M, Lum J, Koh VT, Mak TM, Cui L, Lin RV, Heng D, Leo YS, Lye DC, Lee VJ; Singapore 2019 Novel Coronavirus Outbreak Research Team. Investigation of three clusters of COVID-19 in Singapore: implications for surveillance and response measures. Lancet 2020;395(10229):1039-46. DOI PubMed

3. Jang S, Han SH, Rhee JY. Cluster of coronavirus disease associated with fitness dance classes, South Korea. Emerg Infect Dis 2020;26(8):1917-20. DOI PubMed

4. National Collaborating Centre for Methods and Tools. Rapid review: What is known about the risk of COVID-19 transmission across different indoor settings in the community such as restaurants and gyms? Hamilton (ON): NCCMT; 2020. https://www.nccmt.ca/covid-19/covid-19rapid-evidence-service/30

5. Furuse $Y$, Sando E, Tsuchiya N, Miyahara R, Yasuda I, Ko YK, Saito M, Morimoto K, Imamura T, Shobugawa Y, Nagata $S$, Jindai K, Imamura T, Sunagawa T, Suzuki M, Nishiura $\mathrm{H}$, Oshitani $\mathrm{H}$. Clusters of coronavirus disease in communities, Japan, January-April 2020. Emerg Infect Dis 2020;26(9):2176-9. DOI PubMed

6. Buonanno G, Morawska L, Stabile L. Quantitative assessment of the risk of airborne transmission of SARS-CoV-2 infection: prospective and retrospective applications. Environ Int 2020;145:106112. DOI PubMed

7. Helsingen LM, Løberg M, Refsum E, Gjøstein DK, Paulina Wieszczy P, Olsvik $\varnothing$, Juul FE, Barua I, Jodal HC, Herfindal M, Mori Y, Jore S, Lund-Johansen F, Fretheim A, Bretthauer M, Kalager M; The TRAiN study group. A Randomised Trial of Covid-19 Transmission in Training Facilities. medRxiv 2020.06.24.20138768 [Preprint]. Posted 2020-11-17 (accessed 2020-11-24). DOI
8. Fisher KA, Tenforde MW, Feldstein LR, Lindsell CJ, Shapiro NI, Files DC, Gibbs KW, Erickson HL, Prekker ME, Steingrub JS, Exline MC, Henning DJ, Wilson JG, Brown SM, Peltan ID, Rice TW, Hager DN, Ginde AA, Talbot HK, Casey JD, Grijalva CG, Flannery B, Patel MM, Self WH; IVY Network Investigators; CDC COVID-19 Response Team. CDC COVID-19 Response Team. Community and close contact exposures associated with COVID-19 among symptomatic adults $\geq 18$ years in 11 outpatient health care facilities- united States, July 2020. MMWR Morb Mortal Wkly Rep 2020 Sep;69(36):1258-64. DOI PubMed

9. GISAID. Lineage B.1.1.72 [Internet]. Hixton (UK): Centre for Genomic Pathogen Surveillance; 2020 (accessed 2020-11-24). https://cov-lineages.org/lineages/ lineage_B.1.1.72.html

10. GISAID. cov-lineages/pangolin [Internet]. Hixton (UK): Centre for Genomic Pathogen Surveillance; 2021 (accessed 2021-02-17). https://github.com/cov-lineages/pangolin

11. Government of Saskatchewan. Gyms and fitness facilities guidelines. Guidelines for the re-open Saskatchewan plan [Internet]. Regina (SK): Government of Saskatchewan; 2020 (accessed 2020-11-15). https://www.saskatchewan. $\mathrm{ca} /$ government/health-care-administration-and-providerresources/treatment-procedures-and-guidelines/emergingpublic-health-issues/2019-novel-coronavirus/re-opensaskatchewan-plan/guidelines/gyms-and-fitness-facilitiesguidelines

12. Isaacs D, Britton $P$, Howard-Jones A, Kesson A, Khatami A, Marais B, Nayda C, Outhred A. To what extent do children transmit SARS-CoV-2 virus? J Paediatr Child Health 2020;56(6):978-9. DOI PubMed

13. Riediker M, Morawska L. Low exhaled breath droplet formation may explain why children are poor SARS-CoV-2 transmitters. Aerosol Air Qual Res 2020;20(7):1513-5. DOI 